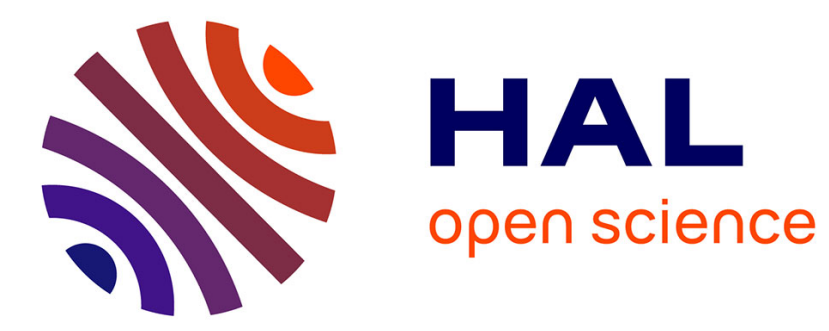

\title{
Multi-barrier height characterization and DLTS study on Ti/W 4H-SiC Schottky Diode
}

Teng Zhang, Christophe Raynaud, Dominique Planson

\section{To cite this version:}

Teng Zhang, Christophe Raynaud, Dominique Planson. Multi-barrier height characterization and DLTS study on Ti/W 4H-SiC Schottky Diode. Materials Science Forum, 2019, 963, pp.576-579. 10.4028/www.scientific.net/MSF.963.576 . hal-02436812

\section{HAL Id: hal-02436812 https://hal.science/hal-02436812}

Submitted on 13 Jan 2020

HAL is a multi-disciplinary open access archive for the deposit and dissemination of scientific research documents, whether they are published or not. The documents may come from teaching and research institutions in France or abroad, or from public or private research centers.
L'archive ouverte pluridisciplinaire HAL, est destinée au dépôt et à la diffusion de documents scientifiques de niveau recherche, publiés ou non, émanant des établissements d'enseignement et de recherche français ou étrangers, des laboratoires publics ou privés. 


\title{
Multi-barrier height characterization and DLTS study on Ti/W 4H-SiC Schottky Diode
}

\author{
Teng ZHANG ${ }^{a}{ }^{*}$, Christophe Raynaud ${ }^{b}$ and Dominique Planson ${ }^{c}$ \\ Univ Lyon, INSA Lyon, École Centrale de Lyon, Université Claude Bernard Lyon 1, \\ CNRS, AMPERE, F-69621 Villeurbanne, France \\ a teng.zhang@insa-lyon.fr, b christophe.raynaud@insa-lyon.fr, c dominique.planson@insa-lyon.fr
}

Keywords: SiC; Schottky; multi barrier; DLTS; annealing; I-V; C-V; stress

\begin{abstract}
Schottky barrier height (SBH) has been characterized on 4H-SiC Schottky diodes with metal contact of $\mathrm{Ti} / \mathrm{W}$ by Current-Voltage (I-V) and Capacitance-Voltage (C-V) measurements between $80 \mathrm{~K}$ and $400 \mathrm{~K}$. Multi-barrier has been recognized and calculated according to different models. No clear difference has been found between single barrier diode and diode with multi-barrier from DLTS tests. Evolution on the I-V characteristics has been observed after high temperature annealing. The effect of annealing at room temperature (RT) and high temperature DLTS scan (stress under high temperature) have also been studied on both static characteristics and DLTS results.
\end{abstract}

\section{Introduction}

Inhomogeneous barrier, which manifests as abnormal high current under low forward bias namely double or multi barrier phenomenon, has attracted attention among Schottky barrier diode (SBD) characterization for a long history, and not restricted to SiC devices. Similar phenomenon has been reported especially at low temperature, and it was highlighted that these 'non-ideal' diodes occurred regardless of growth technique, pre-deposition cleaning method, or contact metal [1-2]. Schottky barrier height $(\mathrm{SBH})$ has been characterized on $\mathrm{Ti} / \mathrm{W} 4 \mathrm{H}-\mathrm{SiC}$ Schottky diodes by $\mathrm{I}-\mathrm{V}$ and $\mathrm{C}-\mathrm{V}$ measurements under wide temperature range. The evolution on forward I-V characteristics has been observed and investigated by high temperature annealing and accelerated stress with the help of Deep Level Transient Spectroscopy (DLTS).

\section{Experimental Setup}

Three 4H-SiC SBDs with metal contact of Ti/W have been investigated and labeled diode \#1, \#2 and \#3. All SBDs with a square surface of $2.48 \mathrm{~mm}^{2}$ were provided by our collaborator with a process of etch after sputtering. I-V and C-V characteristic have been measured in the cryostat between $80 \mathrm{~K}$ and $400 \mathrm{~K}$ with a step of $20 \mathrm{~K}$ in the dark to rule out the influence of light, with a Keithley K2410 and a Keysight E4990A Impedance Analyser. Forward characteristics have been measured every $0.01 \mathrm{~V}$ with a limitation of $30 \mathrm{~mA}$ which is high enough for the study of exponential region of the diodes. Applied voltage varies from $0 \mathrm{~V}$ to $-5 \mathrm{~V}$ with a frequency of $100 \mathrm{kHz}$ to extract the linear performance on the plot of $1 / \mathrm{C}^{2}$ vs. V. On top of that, the DLTS tests have been realized with FT-1230 HERA DLTS (High Energy Resolution Analysis Deep Level Transient Spectroscopy) system provided by PhysTech.

\section{Results and discussion}

SBH Identification on Diode \#1. As shown in Fig. 1, the forward I-V curves of diode \#1 present a second barrier for temperatures below $240 \mathrm{~K}$. The ideality factor $\mathrm{n}$ and saturation current Is could be extracted from the 'linear' region in forward characteristic. 
Modified Richardson plot. With the help of shallow doping concentration $\mathrm{N}_{D}$ and barrier height calculated from $\mathrm{C}-\mathrm{V}$ measurements, flat-band $\mathrm{SBH}\left(\Phi_{\mathrm{BF}}\right)$ and the modified Richardson constant $\mathrm{A}^{*}$ can be obtained according to modified Richardson plot, as illustrated in Fig. 2 [3]. Two distinct $\Phi_{\mathrm{BF}}$ are extracted with a higher SBH of $1.20 \mathrm{eV}$ over the whole temperature range studied and the other $\mathrm{SBH}$ of $0.72 \mathrm{eV}$ shows up at low temperature only. If considering the constant $\mathrm{A}^{*}$ over both paths and the effective surface of low SBH region should account for $10^{-8}$ of the total area. However, its influence on forward I-V characteristics could be the major factor especially at low temperature.

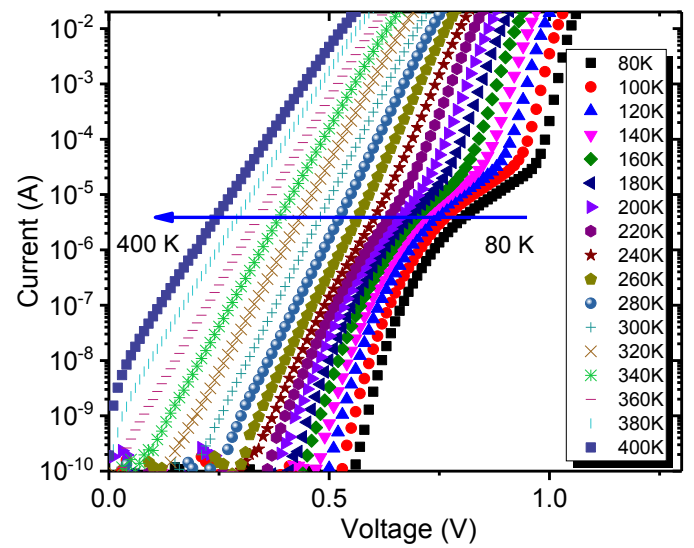

Fig. 1. Forward I-V characteristic on diode \#1 between $80 \mathrm{~K}$ and $400 \mathrm{~K}$.

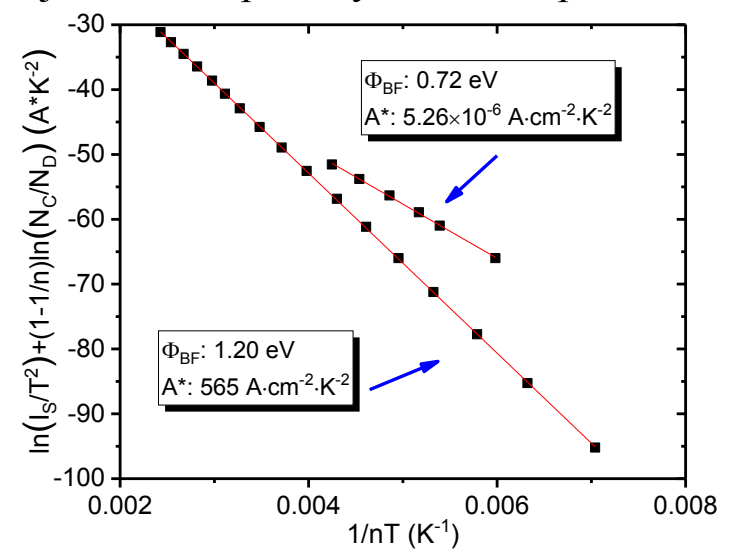

Fig. 2. Modified Richardson plot based on $\Phi_{\mathrm{BF}}$ for diode \#1.

Gaussian Distribution Model. Assuming that SBH is normally distributed on Gaussian [4], its mean barrier height and standard deviation can be extracted with the zero-bias barrier height $\Phi_{0}$ calculated based on the $\mathrm{A}^{*}$ obtained above, as shown in Fig. 3.

Potential Fluctuation Model. To explain the temperature dependence of the ideality factor, Werner et al. assumed the SBH to be normally distributed, but the mean and standard deviation vary linearly with voltage [5]:

$$
\bar{\Phi}_{B}=\bar{\Phi}_{B 0}+\rho_{2} V . \text { and } \sigma_{S}^{2}=\sigma_{S 0}^{2}+\rho_{3} V .
$$

Those parameters can be calculated with the plot illustrated in Fig. 4.

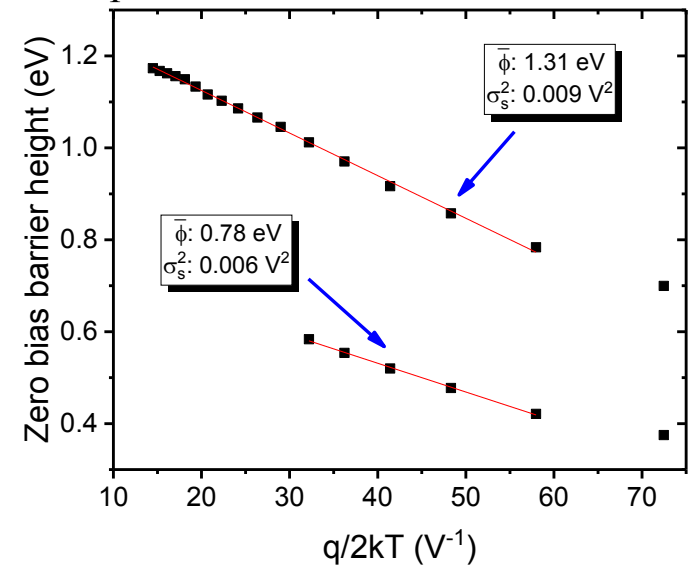

Fig. 3. $\Phi_{0}$ as a function of $\mathrm{q} / 2 \mathrm{kT}$ on $\# 1$.

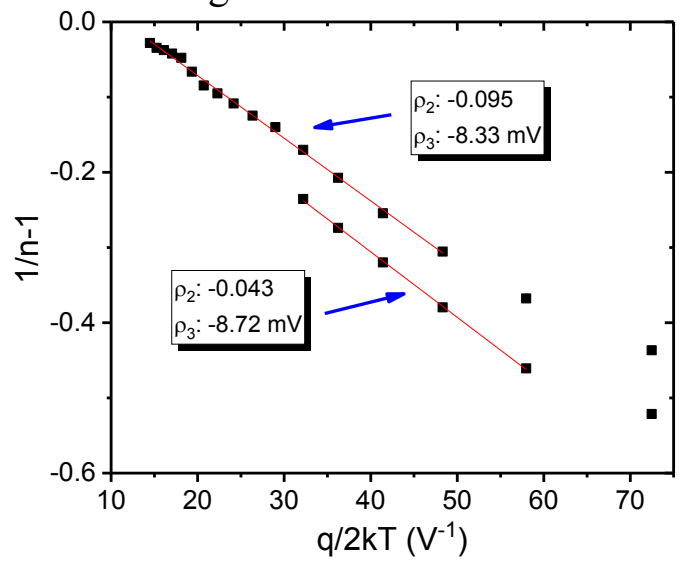

Fig. 4. 1/n-1 as a function of $\mathrm{q} / 2 \mathrm{kT}$ on $\# 1$.

Discussion. Two different SBHs are recognized from various models. However, unlike $\Phi_{0}$ that is strongly depend on temperature as shown in Fig. 3, the recalculated $\Phi_{\mathrm{BF}}$ at each temperature based on its definition almost keeps constant and is closed to the SBH obtained by $\mathrm{C}-\mathrm{V}(\sim 1.19 \mathrm{eV})$. In addition, similar behavior between Gaussian distribution and potential fluctuation model is forecasted.

I-V Characteristics Evolution on Diode \#2. During DLTS study, several temperature scans have been applied on diode \#2 as shown in Fig. 5 with that of diode \#1 as a reference. Even with almost the same results on DLTS spectra which indicates that no clear difference on trap levels can be found among the temperature investigated, the I-V characteristics could be rather different, as illustrated in 
Fig. 6. Considering that samples are reserved in the vacuum dark chamber of DLTS system, the evolution of I-V characteristic could only result from the multi DLTS temperature scan applied.

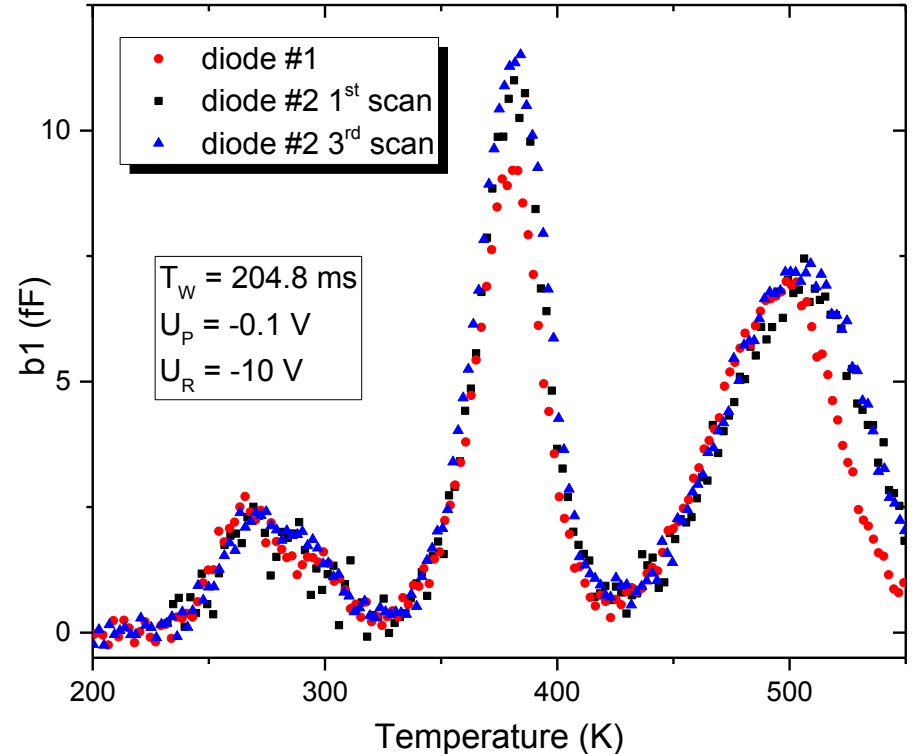

Fig. 5. DLTS signal (correlation b1) between $60 \mathrm{~K}$ and $550 \mathrm{~K}$ on diode \#1 and \#2 before and after double barrier shown up. The DLTS parameters selected for all the measurements are marked in the plot. No remarkable difference shows up on current DLTS between $20 \mathrm{~K}$ and $180 \mathrm{~K}$ either (not shown here).
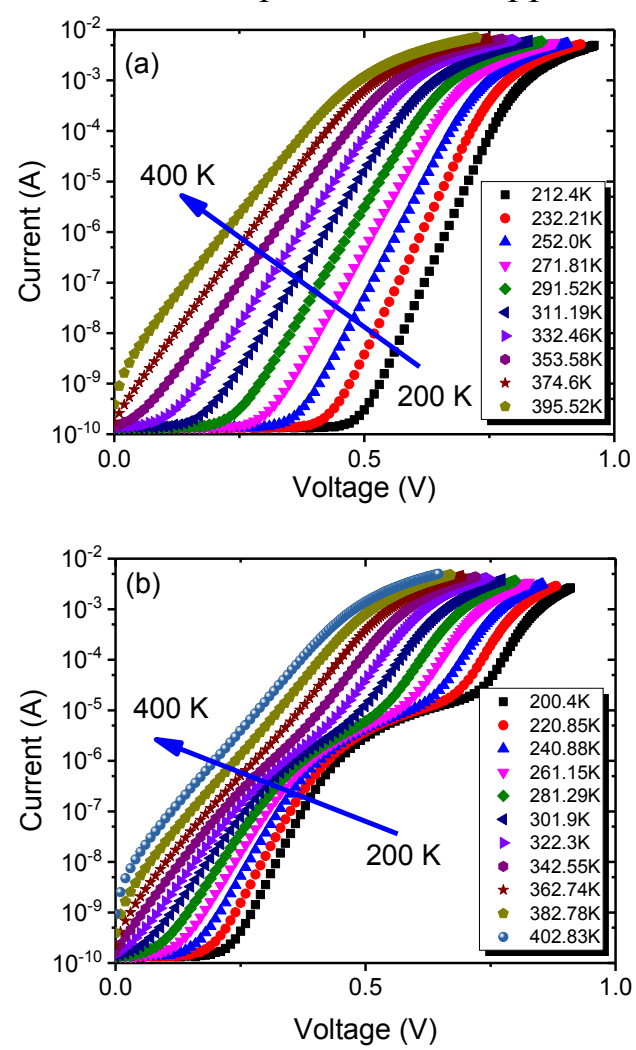

Fig. 6. Forward I-V curves on diode \#2 during (a): $1^{\text {st }}$ scan and (b): $3^{\text {rd }}$ scan.

Table 1. Measurement steps and their conditions on diode \#3.

\begin{tabular}{|c|c|c|c|c|}
\hline Step & Measure & Temperature $[\mathrm{K}]$ & Condition & Label \\
\hline \hline 1 & I-V & 60 & - & IV-0 \\
\hline 2 & DLTS scan & $60-300$ & $2.5 \mathrm{~h}$ & Tempscan-1 \\
\hline 3 & I-V & 60 & - & IV-1 \\
\hline 4 & Annealing & 550 & AC track signal, 200 min & - \\
\hline 5 & I-V & 60 & - & IV-2 \\
\hline 6 & DLTS scan & $60-300$ & $2.5 \mathrm{~h}$ & Tempscan-2 \\
\hline 7 & Annealing & 300 & Bias $=-0.1 \mathrm{~V}, 3$ day & - \\
\hline 8 & I-V & 60 & - & IV-3 \\
\hline 9 & DLTS scan & $60-550$ & $6 \mathrm{~h}$ & Tempscan-3 \\
\hline 10 & I-V & 60 & - & IV-4 \\
\hline 11 & DLTS scan & $60-550$ & $\mathrm{UP}=0.5 \mathrm{~V}, 6 \mathrm{~h}$ & Tempscan-4 \\
\hline 12 & I-V & 60 & - & IV-5 \\
\hline 13 & DLTS scan & $60-300$ & $3 \mathrm{~h}$ & Tempscan-5 \\
\hline 14 & Annealing & 300 & Bias $=-0.1 \mathrm{~V}, 100 \mathrm{~h}$ & - \\
\hline 15 & I-V & 60 & - & IV-6 \\
\hline 16 & DLTS scan & $60-300$ & $3 \mathrm{~h}$ & Tempscan-6 \\
\hline
\end{tabular}


Annealing and Stress Investigation on Diode \#3. In order to investigate the origin of the evolution on I-V characteristics, additional measurements have been adopted on diode \#3 as listed in Table 1.

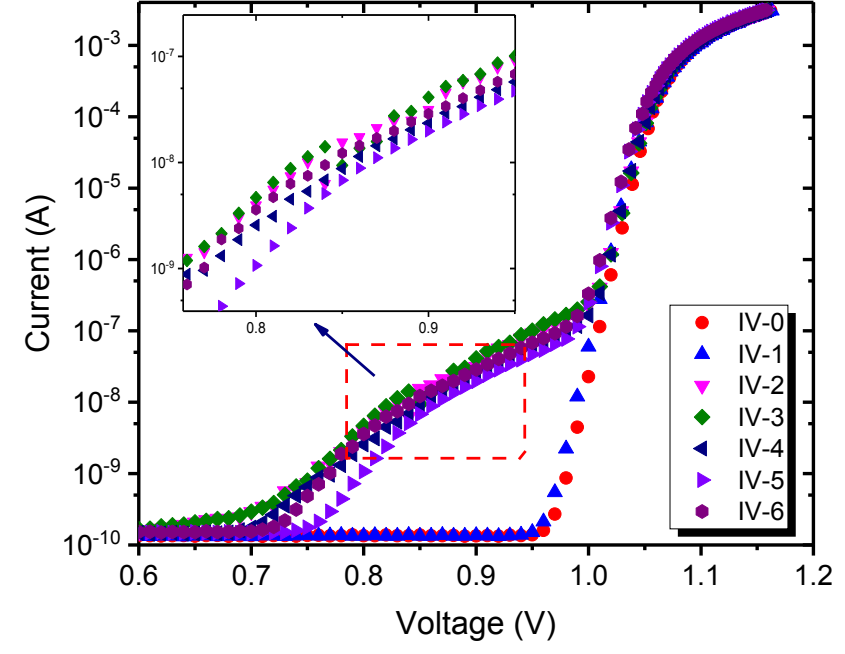

Fig. 7. Evolution on I-V characteristic on \#3.

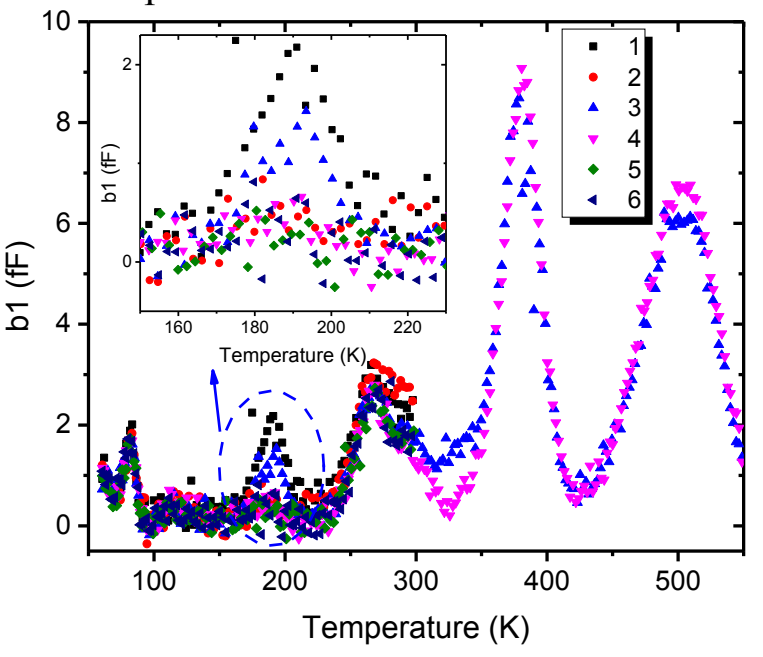

Fig. 8. Evolution on DLTS on diode \#3.

Evolution on Forward I-V Characteristics. Fig. 7 shows the measured I-V at $60 \mathrm{~K}$ on diode \#3 with labels illustrated in Table 1. It is clear that low temperature DLTS scans have no influence on I-V curve. However, multi-barrier shows up after high temperature annealing, while annealing at RT has no obvious effect on I-V characteristic. Furthermore, high temperature DLTS scans reshape the I-V curve, which indicates that possible pinch-off of low SBH takes place under both high temperature and bias stress, this could be annealed at RT to some degree.

Evolution on DLTS signals. Those DLTS signals (b1) are illustrated in Fig. 8. It is worth highlighting that the peak at around $190 \mathrm{~K}$ of the DLTS signal which can be annealed at high temperature will recover at RT. Meanwhile, this defect level is eliminated after high temperature DLTS scan, or in other words the accelerated bias stress due to high temperature, and no recovery is found after RT annealing.

\section{Summary}

Multi-barrier has been identified by different models on 4H-SiC Ti/W SBD. No trap level found can contribute to the evolution on multi-barrier formation. However, a second barrier shows up after annealing at high temperature, and cannot be annealed at RT. High temperature DLTS scan, which regarded as accelerated bias stress owing to high temperature, also influences the SBH by reforming the low SBH region, and can be recovered a little at RT. High temperature DLTS scan will also wipe out several defect levels, while annealing at high temperature has only temporary effects on them. Furthermore, the characterization of metal/semiconductor interface is preferred in the future work.

\section{Acknowledgement}

Authors acknowledge the financial support of the Chinese Scholarship Council (CSC) n. 201506090154 as well as National Center of Microelectronics of Barcelona and Caly Technologies.

\section{References}

[1] Ł.Gelczuk, et al., Solid-State Electronics. 2014. 99: p. 1-6.

[2] D. J. Ewing, et al., Semicond. Sci. Technol. 2007. 22(12): p. 1287-1291.

[3] S. Chand, and J. Kumar, Semicond. Sci. Technol. 1995. 10(12): 1680.

[4] Y. Song, et al., Solid-State Electronics. 1986. 29: p. 633-638.

[5] J. H. Werner, and H. H. Güttler, J. Appl. Phys. 1991. 69(3): 1522-1533. 